NFL REPORT TQE 15

CALIBRATION OF REFERENCE ANTENNAS FOR VECTOR MEASUREMENT OF GAR

D J BOUNDS, A P GREGORY, G REVILLOD, M G COX AND D ALLAL

DECEMBER 2020

Department for

Department for
Business, Energy
\& Industrial State

Funded ar ats 



\title{
Calibration of reference antennas for vector measurement of SAR
}

\author{
D J Bownds, A P Gregory, G Revillod, M G Cox, D Allal \\ G Revillod is with Kapteos SAS, 354 voie Magellan, \\ Z. A. Alpespace, 73800 Sainte-Hélène-du-Lac, France \\ D Allal is with Laboratoire National de Métrologie et d'Essais, \\ Trappes, France
}

December 2020

\begin{abstract}
Vector-based instrumentation for the determination of Specific Absorption Rate (SAR) uses measurements of the complex E-field inside a phantom at multiple locations. Re-construction algorithms are used to calculate the SAR and its peak spatial value. The required measurements can be made by using an E-field vector probe that is controlled by a robot, or by using a static array of vector probes (for example, dipole antennas and receivers). The latter approach potentially offers much reduced measurement times, which is particularly advantageous for type-approval tests on smart phones as these can have 30 or more transmitting modes. To enable traceable measurement of SAR, an array-based system requires calibration data for its individual antennas, which can be obtained by exposing the individual antennas to a characterised complex E-field from a stable antenna (which will be referred to as a reference antenna). This report describes the process for characterising a reference antenna: traceable mapping of complex E-fields inside a liquid phantom which is illuminated by the antenna from beneath. The measurements of complex E-field were made by using an electrooptic probe that has been calibrated by using a traceable waveguide system.
\end{abstract}


NPL Report TQE 15

(C) Queen's Printer and Controller of HMSO, 2020

ISSN 1754-2995

DOI https://doi.org/10.47120/npl.TQE15

National Physical Laboratory,

Hampton Road, Teddington, Middlesex, United Kingdom TW11 0LW

Extracts from this report may be reproduced provided the source is acknowledged and the extract is not taken out of context

Approved on behalf of NPLML by Richard Dudley, Science Area Leader 


\section{Contents}

1 Introduction $\quad 1$

1.1 Vector E-field probes . . . . . . . . . . . . . 2

2 Calibration of vector probes in waveguide cells 3

$\begin{array}{lll}3 & \text { Scanned measurement of E-field in the reference phantom } & 8\end{array}$

4 Measurement model and input parameters 11

4.1 Power calibration to give the calibration constant $C$. . . . . 13

4.2 Characterisation of the waveguide cell to give waveguide power transmission $W_{\mathrm{T}} \ldots \ldots \ldots \ldots \ldots \ldots$

4.3 Measurement of the dielectric permittivity and conductivity of the liquid phantom . . . . . . . . . . . . 16

4.4 Measurement of calibration factor $F$ by using a waveguide cell . 16

4.5 Measurement of vector E-fields in the reference phantom . . . . 17

5 Evaluation of the uncertainty associated with measured Efields in the reference phantom

5.1 Partial derivatives required for calculating uncertainty associated with $F$ measured in the waveguide cell . . . . . . . . . . 21

5.2 Identification of uncertainty contributions associated with measurement of $F(z)$ with the waveguide system . . . . . . . . . . . 22

$\begin{array}{llr}6 & \text { Results } & 26\end{array}$

$\begin{array}{lll}7 & \text { Conclusion } & 31\end{array}$

$\begin{array}{ll}\text { References } & 32\end{array}$ 

NPL Report TQE 15

\section{Introduction}

IEC Standard 62209-3 [1] describes assessment of Specific Absorption Rate (SAR) by using vector-measurement-based systems that measure complex Efield inside a phantom at multiple locations. Such a system allows instrumentation based on a static array of dipole antennas and vector receivers to be developed for rapid measurement of SAR, and greatly reduces the amount of time needed to assess SAR compared to systems based on mechanical scanning of a single E-field probe with a robot. Rapid measuring systems are especially valuable for assessing the SAR of modern smartphones, which may have as many as 30 transmitting modes. Vector-based systems for measuring SAR use a 3D field-reconstruction algorithm [2] to obtain the SAR distribution inside the phantom. Metrological field reconstruction requires traceable calibration of the individual antennas and receivers in the array and is achieved by illuminating them with known complex E-fields from a stable antenna (which will be referred to as the reference antenna). Therefore, a prior calibration process is needed to map the complex E-fields set up by the reference antenna inside the phantom.

This report describes the use of NPL test facilities to calibrate reference antennas that were designed and manufactured by the Art-Fi company ${ }^{1}$ and are of the Vivaldi type. Maps of complex E-fields over a 2D plane inside a polymer tank of elliptical cross section tank that contains a liquid phantom (here referred to collectively as the reference phantom) were obtained while the tank was illuminated with RF power. Calibration data for antennas that operate at $900 \mathrm{MHz}$ and $2450 \mathrm{MHz}$ are presented in this report, but it was not possible to obtain satisfactory data for an antenna that operates at $5200 \mathrm{MHz}$ as the signal-to-noise ratio from the available instruments was too high.

The process for calibrating each reference antenna entails two main steps:

1. Calibration of the magnitude response of a probe that can be used for mapping vector E-fields. The sensitivity of E-field probes depends on the dielectric permittivity of the surrounding medium, so they must be calibrated against calculable fields while immersed in a phantom liquid. The permittivity and conductivity of the liquid must comply with the specifications given in international standards for SAR measurement. Waveguide systems for calibration of scalar E-field probes were developed

\footnotetext{
${ }^{1}$ Art-Fi SA, Orsay, France
} 
NPL Report TQE 15

some years ago [3]. A waveguide system that has been modified to allow calibration of vector E-field probes is described in this report.

2. Mapping of vector electric field over a 10 plane (X and $\mathrm{Y}$ directions) at a fixed height ( $\mathrm{Z}$ direction) inside the phantom by using a vector E-field probe that is calibrated for in-phantom measurements. Measurements in reference phantoms illuminated by reference antennas will be made.

The signal paths for the two steps are the same (that is, the waveguide system is substituted by the reference antenna and phantom while retaining all components in the signal path). This enables the input power level at the reference antenna, and the E-field inside the reference phantom, to both be measured traceably. Vector measurements are made, but measured phases are only relative (that is only meaningful as variations) as the location of the phase reference plane is not defined.

The outcome of the process is a set of traceable maps of the vector E-fields generated by stable reference antennas in a specified plane inside phantoms for a specified input power. The two main steps described above are described in Sections 2 and 3. Section 4 describes the measurement model in greater detail. Section 5 presents evaluations of the uncertainty associated with the measured in-phantom E-fields generated by the reference antennas.

\section{$1.1 \quad$ Vector E-field probes}

In the work described, the E-field probe was a single-axis electrooptic probe manufactured by Seikoh-Giken (model CS-1504). This probe contains no metal other than a miniature dipole that is fabricated on a lithium niobate substrate. Laser light at wavelength $1500 \mathrm{~nm}$ is modulated by the microwave signal that is picked up by the probe. It is coupled via optical fibre to a receiver unit that demodulates the signal by using a high-speed photodiode. The signal, after amplification, is measured by a vector receiver. An Agilent 8753ES Vector Network Analyser (VNA) was used as source and receiver in this work. 10

Each probe has optical waveguides (manufactured by doping the lithium niobate substrate) that have a Y-configuration to form a reflection-mode MachZehnder structure. The amount of transmitted light is determined by optical interference, which enables modulation by applied electric fields as a result of the electrooptic effect. During manufacture each device is tuned to obtain 
approximately $50 \%$ transmission with no DC field applied. Electrooptic probes are by nature costly to manufacture and sensitive to shock. The electrooptic probe used in this work is very small (dipole antennas approximately $2 \mathrm{~mm}$ in length) to minimise disturbance to fields being measured; therefore the detection systems must have high sensitivity. Measurements must be made with the VNA at its lowest IF bandwidth setting $(10 \mathrm{~Hz})$ to obtain sufficient signal-to-noise ratio.

An advantage of using a miniature vector probe is that the E-field components $E_{x}, E_{y}$ and $E_{z}$ are related by $E_{x}+E_{y}+E_{z} \approx 0$. Therefore, $E_{z}$ can be calculated if $E_{x}$ and $E_{y}$ are known [4], i.e. three field components can be obtained from two measurements.

\section{Calibration of vector probes in waveguide cells}

Waveguide cells (Figure 1) for calibration of scalar probes are described by Hamada and Watanabe [3] and in international standards [5, 6]. These systems use a leakproof dielectric window that is placed at the boundary of waveguide sections filled by air (lower) and liquid phantom (upper). To optimize the power transfer into the phantom, NPL waveguide cells use a two-layer matching window [7]. Tween-based phantoms are used [3]. The permittivity $\epsilon^{\prime}$ and conductivity $\sigma$ of phantoms are checked by using a coaxial sensor [7]. The electric field in the phantom decays with distance from the top of the dielectric window. The E-field magnitude $E(z)$ on the centre axis is given by [3]

$$
E^{2}(z)=\frac{4 P_{\mathrm{WG}}}{a b \delta \sigma} \exp \left(-\frac{2 z}{\delta}\right)
$$

where $P_{\mathrm{WG}}$ is the power flowing in the waveguide at the interface between the liquid and the window, $a b$ is the area of the waveguide, $\delta$ is the penetration depth in the phantom liquid, and $z$ is the distance from the sensing element inside the probe to the top of the dielectric window (see Figure 2).

The penetration depth can be determined from measurement of decay curves in the waveguide cell, but in the work reported here it is calculated from the conductivity measured by using a coaxial sensor. For propagation in 
NPL Report TQE 15

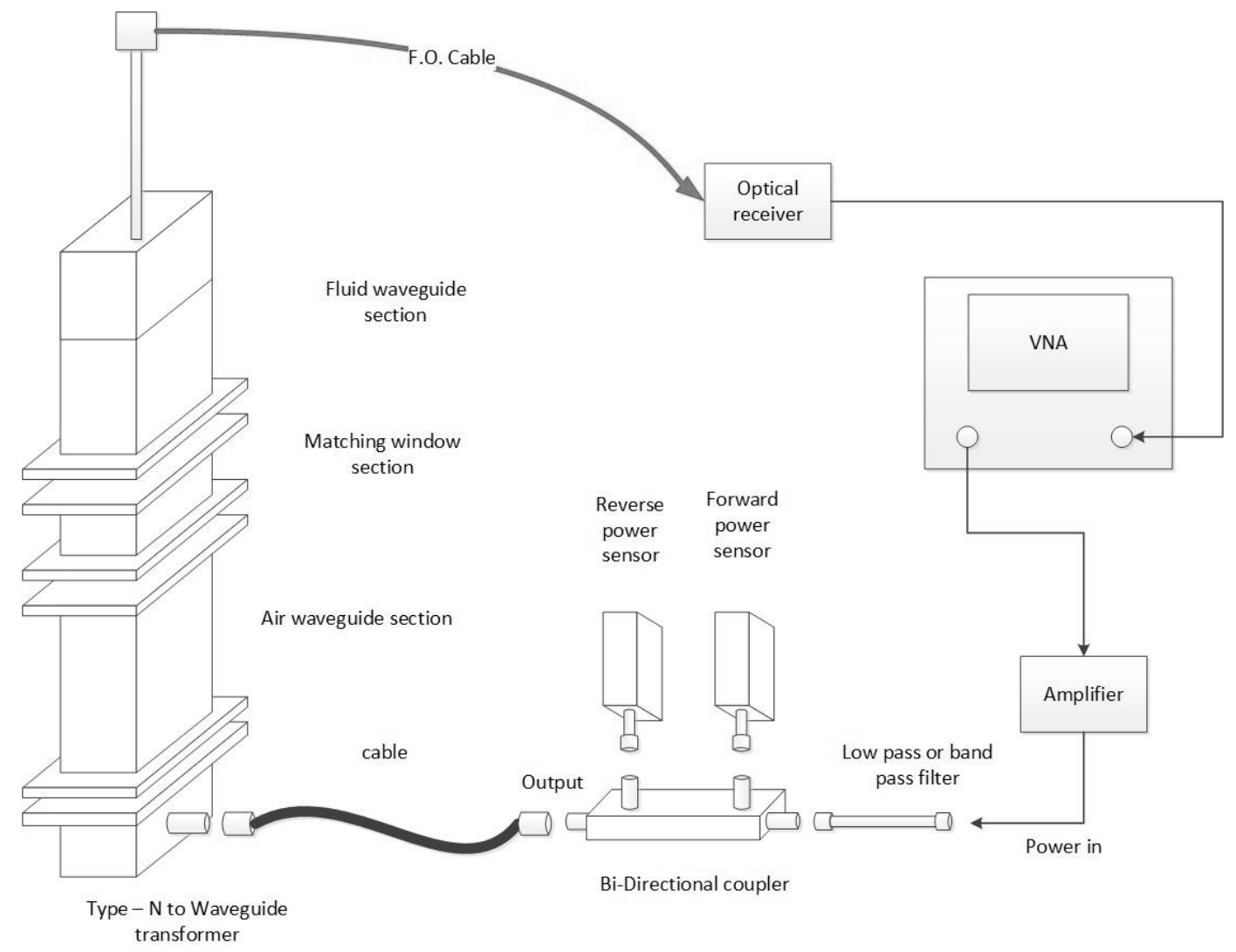

Figure 1: Waveguide cell for calibrating sensors that measure E-field magnitude inside a liquid phantom 
NPL Report TQE 15

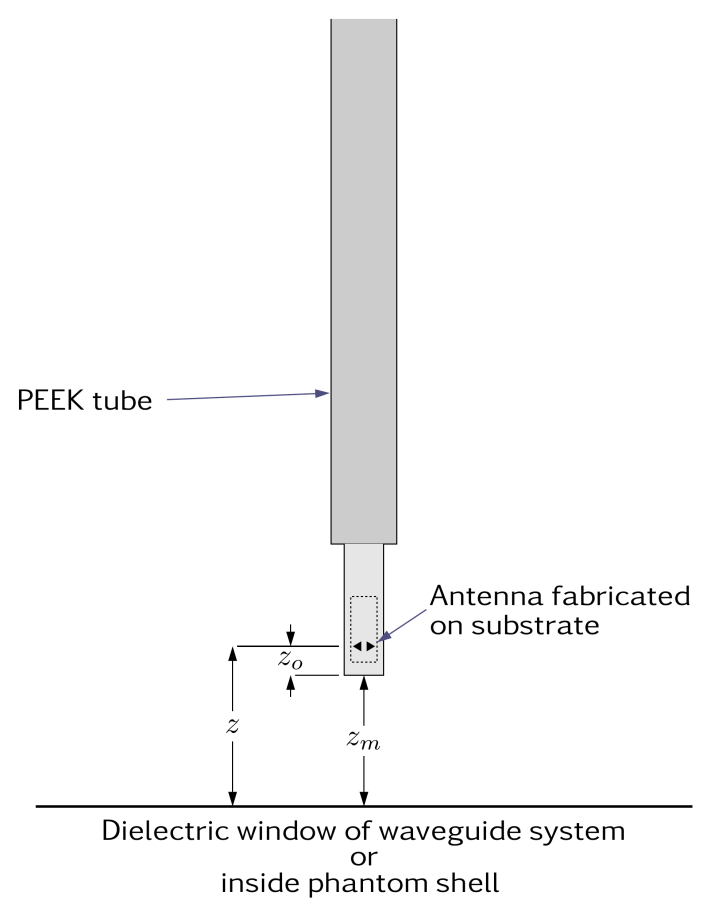

Figure 2: Leakproof probe handle and encapsulated sensing element. This figure defines the quantities $z, z_{m}$ and $z_{o}$. Asterisks are added to $z$ and $z_{m}$ (i.e. they become $z^{*}$ and $z_{m}^{*}$ ) when they refer to measurements in the reference phantom 
NPL Report TQE 15

\begin{tabular}{|c|c|c|c|c|c|}
\hline Frequency & Waveguide & $\epsilon^{\prime}$ & $\sigma$ & \multicolumn{2}{|c|}{$\delta \mathrm{mm}$} \\
\cline { 5 - 6 } $\mathrm{MHz}$ & & & $\mathrm{S} / \mathrm{m}$ & WG-cell & Phantom \\
\hline 900 & WG4 & 41.5 & 0.97 & 36.1 & 35.9 \\
2450 & WG8 & 39.2 & 1.80 & 18.7 & 18.6 \\
5200 & WG12 & 36.0 & 4.66 & 7.00 & 6.96 \\
\hline
\end{tabular}

Table 1: Calculated penetration depths $(\delta)$. The liquid $\epsilon^{\prime} \& \sigma$ data shown is target data from reference [5])

the waveguide cell at frequency $f,[5]$

$$
\begin{aligned}
& \omega=2 \pi f \\
& \alpha=\operatorname{Re}\left\{\sqrt{(\pi / a)^{2}+\mathrm{j} \omega \mu_{o}\left(\sigma+\mathrm{j} \omega \epsilon_{o} \epsilon^{\prime}\right)}\right\}, \\
& \delta=1 / \alpha .
\end{aligned}
$$

For propagation in the phantom tank (which can be considered to be an unbounded medium) [8],

$$
\begin{aligned}
\epsilon^{\prime \prime} & =\sigma /\left(2 \pi f \epsilon_{o}\right), \\
v & =\sqrt{1+\left(\epsilon^{\prime \prime} / \epsilon^{\prime}\right)^{2}}, \\
\alpha & =\omega \sqrt{\epsilon_{o} \epsilon^{\prime} \mu_{o}(v-1) / 2}, \\
\delta & =1 / \alpha .
\end{aligned}
$$

It is found that equations (2) and (3) give very similar values of $\delta$ for the liquid phantom — see Table 1.

For the data shown in Table 1 the simplified form of equation (3),

$$
\delta \approx \frac{2}{\sigma} \sqrt{\frac{\epsilon_{o} \epsilon^{\prime}}{\mu_{o}}},
$$

has sufficient accuracy. In other words, penetration depth is to a good approximation inversely proportional to conductivity.

The power in the waveguide $P_{\mathrm{WG}}$ is fractionally reduced from that at the coupler output $P_{\mathrm{CO}}$ as a result of mismatches and attenuation in the waveguide cell and connecting cable. This reduction is characterised by the power transmission coefficient $W_{\mathrm{T}}$ :

$$
P_{\mathrm{WG}}=P_{\mathrm{CO}} \times W_{\mathrm{T}}
$$


NPL Report TQE 15

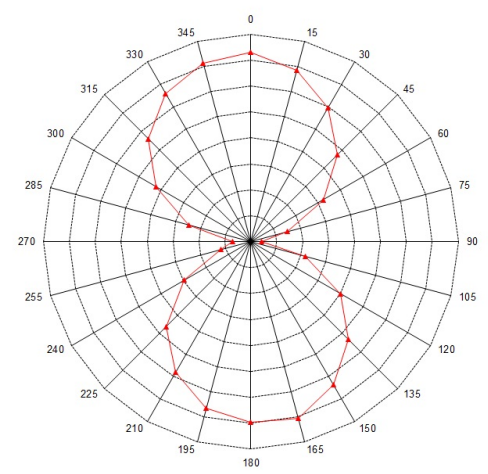

Figure 3: $T$ as a function of rotation of the electrooptic probe. These measurements were made at $900 \mathrm{MHz}$ in a waveguide cell manufactured from UK waveguide size WG4 (equivalent to EIA WR975). The rotation is set to give the highest reading prior to determining $F$

The value of $P_{\mathrm{WG}}$ must be determined by measurement (see Section 4.2). The scalar transmission coefficient $T(z)$ measured by the VNA is given by

$$
T(z)=E(z) / F \text {. }
$$

$T(z)$ is the magnitude of the complex parameter $S_{21}=b_{2} / a_{1}$ (where $a_{1}$ and $b_{2}$ are output complex voltages from vector receivers in the VNA).

$F$ is a calibration constant that characterises the magnitude response of the probe. It is found from measurement of $T$ with the sensing axis of the probe set parallel to the E-field [equation (1)] inside the waveguide cell. The E-field in the waveguide cell is aligned parallel to the waveguide narrow dimension, which allows the sensing axis to be identified by rotating the probe for maximum reading (see Figure 3). The value of $F$ depends on sensitivity of the electrooptic probe and the calibration of the VNA. If the VNA is used uncalibrated (which was the case for the measurements given in this report), $F$ is a function of the factory system error correction of the VNA (and is therefore only valid for the instrument used).

The power level at the coupler output $P_{\mathrm{CO}}$ is also recorded as it is used as the reference level for subsequent measurements of E-field in phantoms. It is chosen (by using the VNA's controls or the setting of the power amplifier that is used to boost the signal) to give acceptable sensitivity while not causing excessive heating in the phantom liquid. 
NPL Report TQE 15

The separation between the probe handle and the window in the waveguide $\left(z_{m}\right)$ is set by the experimenter, but the E-field is measured in the plane of the sensing element (see Figure 2). The offset distance $z_{o}$ must therefore be estimated. One method of estimating $z_{o}$ is to measure the manner (an exponential decay) in which the detected power $\left[E^{2}\left(z_{m}+z_{o}\right)\right]$ varies with $z_{m}$. The value of $z_{o}$ can then be obtained by fitting. In the work described, however, $z_{o}$ was determined using data supplied by the manufacturer of the probe and from the measured dimensions of the probe handle.

In subsequent measurements of E-field in phantoms, $F$ is taken to apply to all measured electric field values, i.e. at any $x, y$ and $z$ values within the scanned region.

In an ideal experiment, $F$ would not vary with the separation between the probe tip and the window inside the waveguide. In practice some variation is observed (Figures 4 and 5). The fact that the probe is built into a probe handle (and not immersed in the liquid directly) is likely to be an underlying cause. A large probe handle was used (diameter $10 \mathrm{~mm}$ at the tip, $z_{o}=5.25 \mathrm{~mm}$ ) to reduce the possibility of damage to the costly electrooptic sensor. These dimensions can be compared to the penetration depth $(\approx 38 \mathrm{~mm}$ at $900 \mathrm{MHz}$, $\approx 18 \mathrm{~mm}$ at $2450 \mathrm{MHz}, \approx 7 \mathrm{~mm}$ at $5200 \mathrm{MHz}$ ). Measurements in the reference phantom that will be presented were obtained at $z=15.25 \mathrm{~mm}$. The value of $F$ at this depth was interpolated from a polynomial of degree 2 fitted to the waveguide data.

Measurements of $\left|S_{21}\right|$ were in the range $-54 \mathrm{~dB}$ to $-64 \mathrm{~dB}$ at $900 \mathrm{MHz}$, which is comfortably above the noise floor $(-80 \mathrm{~dB})$.

\section{Scanned measurement of E-field in the ref- erence phantom}

The E-field pattern is measured in the reference phantom while it is illuminated by the reference antenna (which is connected to the coupler output). The power flow into the antenna (measured at the coupler output) is monitored with the 'forward' power meter. This quantity will be referred to as $P_{\text {ant }}$. Components associated with the signal path such as the VNA, couplers and cables are unchanged, and equation (6) therefore remains valid if the power level is unchanged. In the experiments described in this report the VNA source 


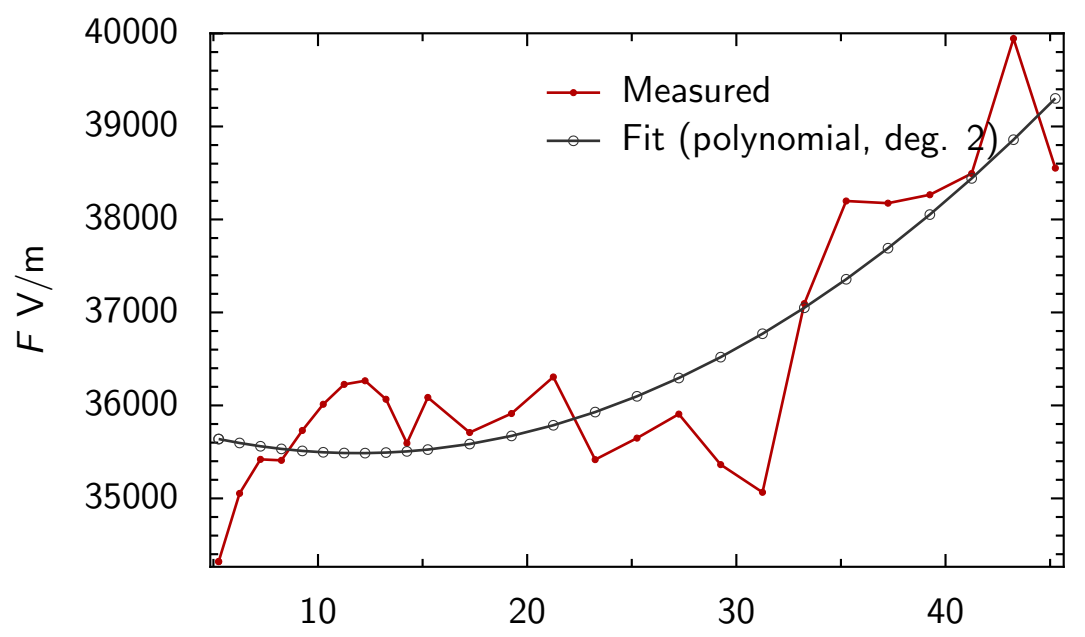

Distance from sensor element to window $\left(z=z_{m}+z_{o}\right) \mathrm{mm}$

Figure 4: $F$ as a function of the gap between the tip of the probe handle and the waveguide window $\left(z_{m}\right)$. Measured in liquid phantom at $900 \mathrm{MHz}$ in waveguide size WG4

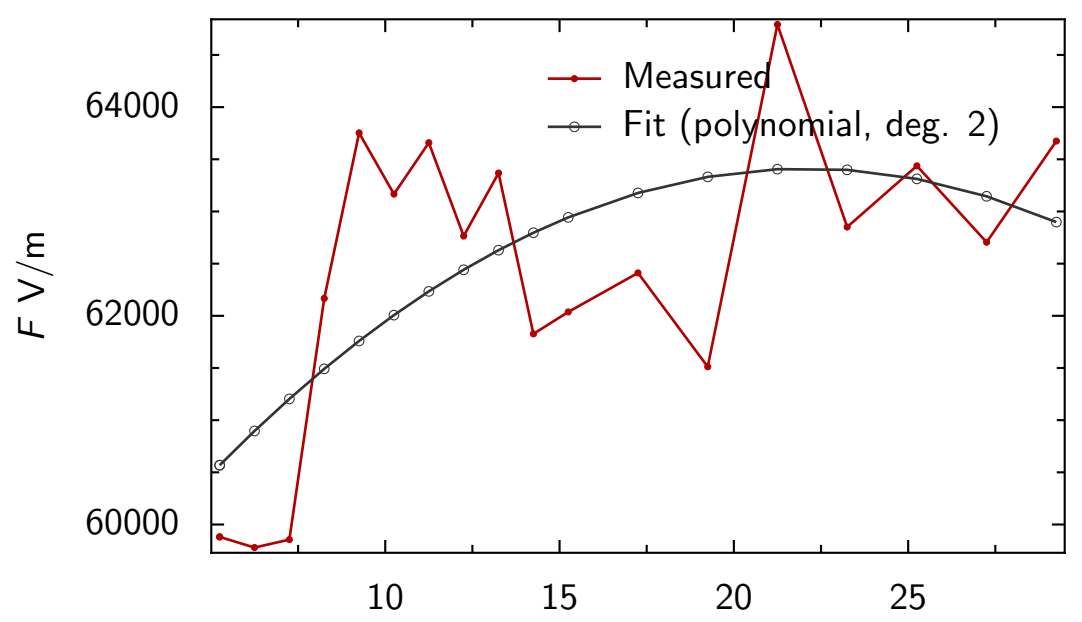

Distance from sensor element to window $\left(z=z_{m}+z_{o}\right) \mathrm{mm}$

Figure 5: $F$ as a function of the gap between the tip of the probe handle and the waveguide window $\left(z_{m}\right)$. Measured in liquid phantom at $2450 \mathrm{MHz}$ in waveguide size WG8 
power was fixed at $0 \mathrm{~mW}$. Measurements of the complex S-parameter $S_{21}$ were made.

It may be recalled that when $F$ was measured by using a waveguide cell, the input power (the quantity $P_{\mathrm{CO}}$ at the coupler output - see Figure 1) was recorded. For the reference phantom measurement the power level at the coupler output (now connected to the antenna) $P_{\text {ant }}$ is not expected to be exactly the same (i.e. $P_{\text {ant }} \neq P_{\mathrm{CO}}$ ) for two reasons: (i) the reference antenna and the waveguide cell present different mismatches, and (ii) $P_{\text {ant }}$ may have been raised (by adjusting amplifier gain) to make the E-field levels (and the signal-to-noise ratio) for the two experiments comparable. The E-field referenced to the input power level, $P_{\mathrm{CO}}$, used when $F$ was determined in the waveguide cell, is

$$
\begin{aligned}
E(z) & =T(z) g F, \\
g & =\left(\frac{P_{\mathrm{CO}}}{P_{\mathrm{ant}}}\right)^{1 / 2} .
\end{aligned}
$$

where $E(z)$ refers to one of the transverse components of E-field ( $E_{x}$ or $E_{y}$ ) according to the angle of rotation of the sensing axis of the probe. $P_{\text {ant }}$ is actually measured at the coupler output, that is the reference antenna and the connecting cable are considered as one assembly.

By using a robot scanning system Figure 6), the E-field inside the reference phantom can be mapped over a plane. The relative phase of measurements can be recorded (i.e. vector measurements can be made).

To obtain sufficient sensitivity, it may be necessary to increase the power level compared with that for the waveguide measurements described in Section 2.

The electric field components in the phantom referenced to the input powerlevel used for the waveguide-cell calibration, $P_{\mathrm{CO}}$, are given by

$$
E_{x}(z)=F P_{\mathrm{CO}}^{1 / 2} T(z) \times P_{\mathrm{ant}}^{-1 / 2} \mathrm{Ang}=0^{\circ}
$$

and

$$
E_{y}(z)=F P_{\mathrm{CO}}^{1 / 2} T(z) \times P_{\mathrm{ant}}^{-1 / 2} \mathrm{Ang}=90^{\circ} .
$$

Power readings are stable so they can conveniently be taken to be constants during each experiment. 


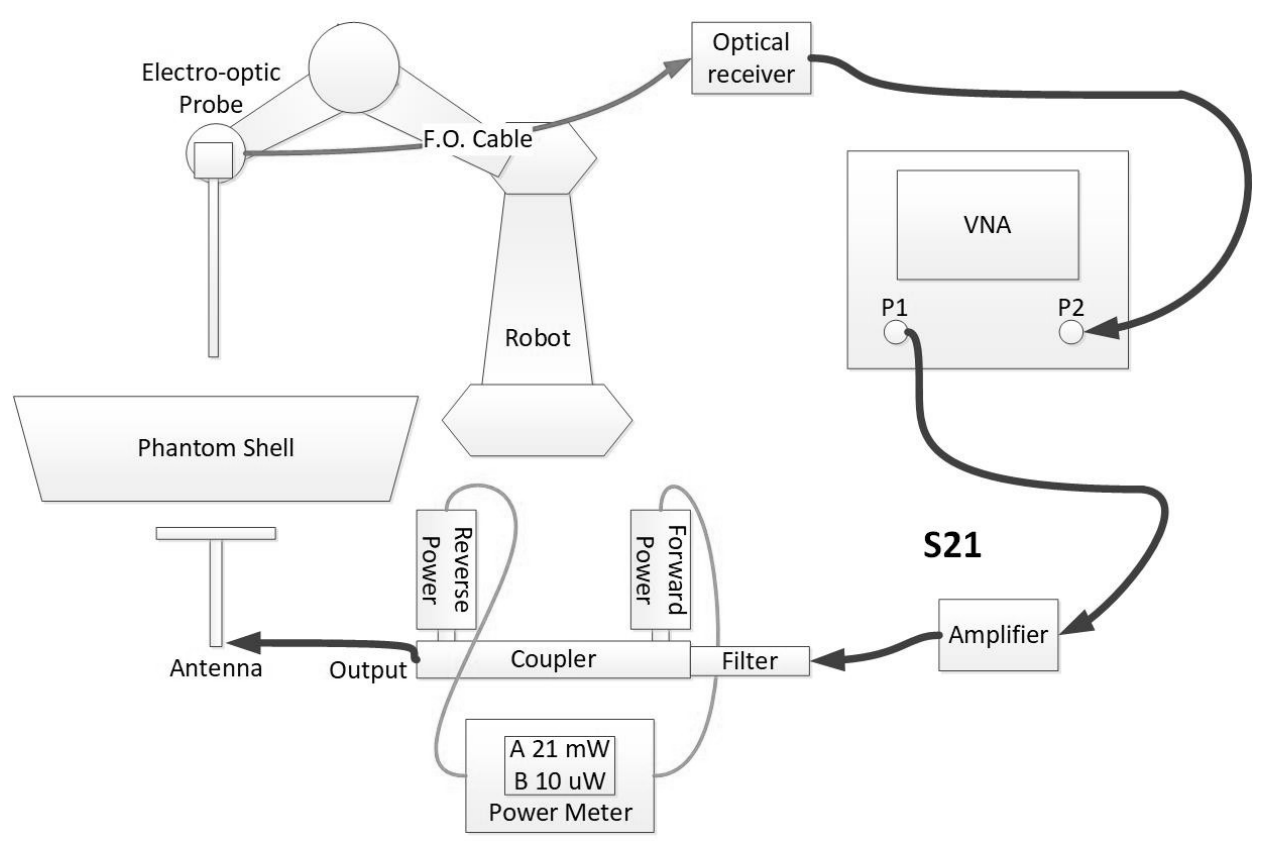

Figure 6: Map of vector E-fields in the reference phantom illuminated by a reference antenna beneath

Figure 7 shows a plot of the magnitude of the X-component of the electric field measured in the reference phantom illuminated from beneath by a reference antenna (model ART-250). As vector measurements were performed, complex values of the $\mathrm{X}$ - and $\mathrm{Y}$-components of the electric field were obtained at each scanned location. The processes by which the E-fields were calculated will be considered in Section 4 .

\section{Measurement model and input parameters}

The experimental procedure will now be considered in greater detail.

Flowcharts (Figure 8 and 9) show the two stages outlined in Section 1. Some preliminary measurements are needed to determine the quantities $C$ and $W_{\mathrm{T}}$, which provide the route to traceability for the E-field established in the waveguide. Measurement of the permittivity $\epsilon^{\prime}$ and conductivity $\sigma$ of the liquid phantom is also considered as these quantities are needed for calculating the penetration depth, and hence the depth-dependence of the E-field in the phantom. They would normally be expected to meet specifications for tissue- 
NPL Report TQE 15

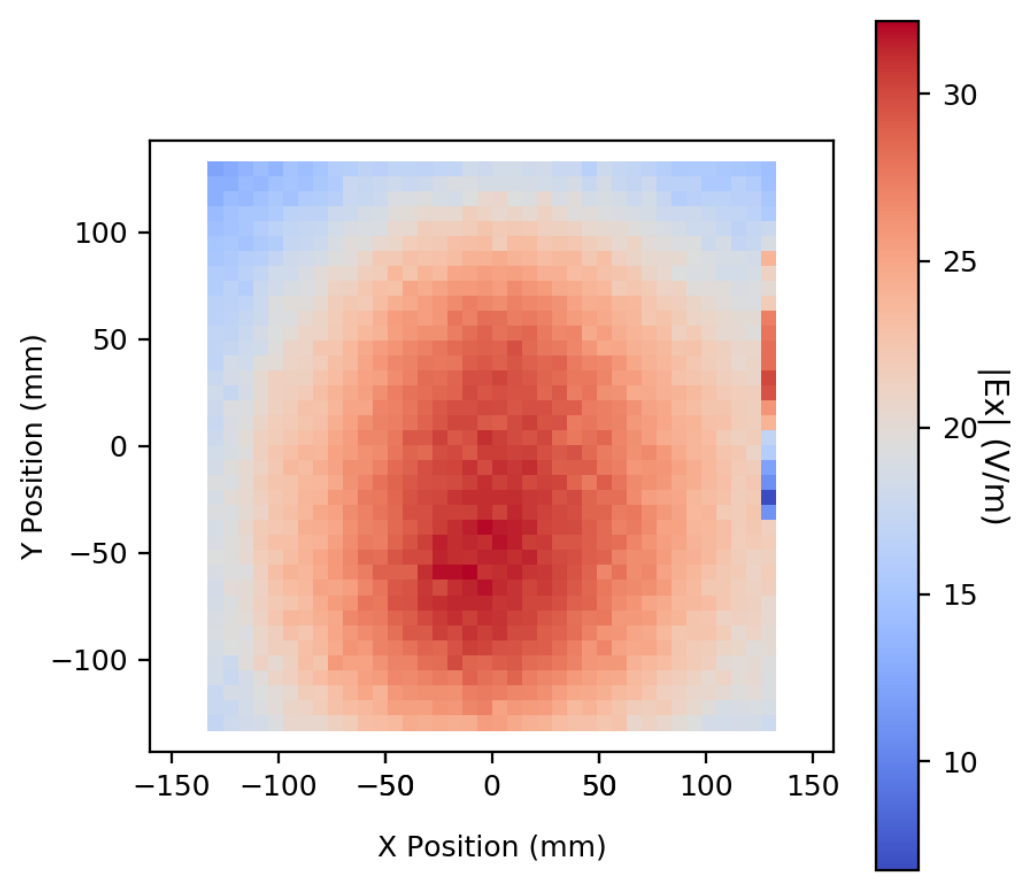

Figure 7: Colour map of the magnitude of the X-component $\left(\left|E_{x}\right|\right)$ of the Efield in the reference phantom at height $z=10 \mathrm{~mm}$. This data was obtained for reference antenna model ART-250 at $900 \mathrm{MHz}$. The antenna was $10 \mathrm{~mm}$ beneath the phantom. They are determined for an input power $\left(P_{\mathrm{CO}}\right)$ of $1.66 \mathrm{~W}$ 
equivalent materials given in international standards for SAR measurement $[9]$.

\subsection{Power calibration to give the calibration constant $C$}

The unit-less calibration constant $C$ is the power at the coaxial output of the coupler per unit power read at the 'forward' side-arm power meter. The power indicated by the 'reverse' power meter is monitored to ensure that it is low-valued (e.g. $\approx 0.1 \%$ of the 'forward' power). The value of $C$ obtained is specific to the particular coupler and 'forward' power meter (neither of which needs to be calibrated otherwise):

$$
C=\frac{\mathrm{CF} \times\left(1-\Gamma^{2}\right) \times P_{\text {output }}}{P_{\text {side_arm }}} \text { CAL }
$$

$C$ is determined from power readings made with a calibrated power meter that is attached temporarily to the coupler coaxial output. The data needed is as follows:

CF The calibration factor of the calibrated power meter (a unit-less quantity $\approx 1$ ) at the measured frequency.

$\Gamma \quad$ The reflection coefficient at the input of the calibrated power meter.

$P_{\text {output }} \quad$ The value read by the calibrated power meter $(\mathrm{W})$.

$P_{\text {side_arm }}$ The power $(\mathrm{W})$ displayed by the 'forward' side arm power meter.

\subsection{Characterisation of the waveguide cell to give waveg- uide power transmission $W_{\mathrm{T}}$}

The unit-less quantity $W_{\mathrm{T}}$ represents the waveguide power transmission between the coaxial connector and the interface between the liquid-filled section and the matching window, i.e. the fraction of the power that is not reflected or dissipated. It can be obtained by characterising the adaptor and matching window by using a VNA. In practice, values very close to unity are obtained (e.g. 0.995) so this is not a significant factor. 
NPL Report TQE 15

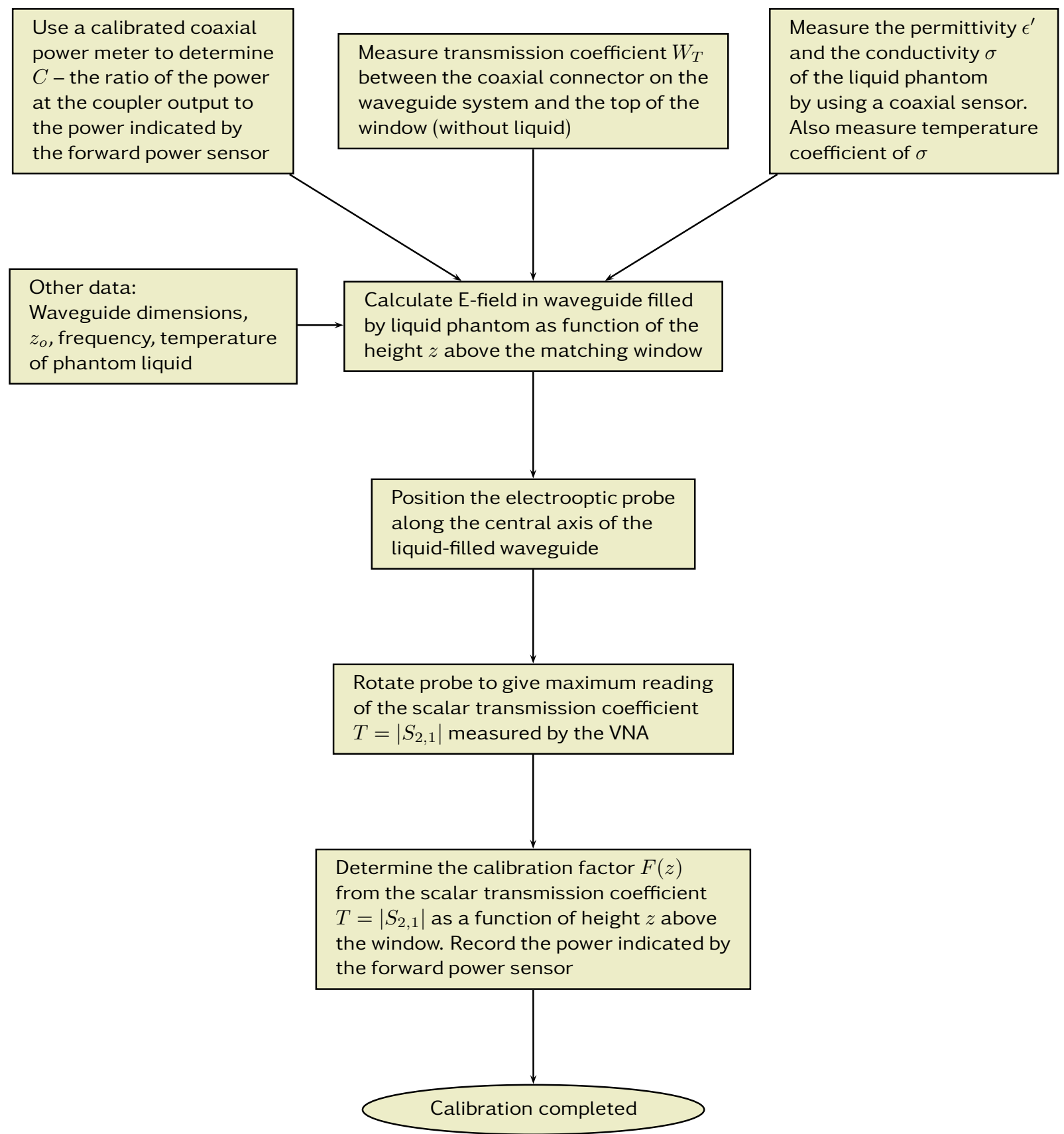

Figure 8: The steps required to calibrate the electrooptic probe and the detection system by using a calculable waveguide cell (see Figure 1) 
NPL Report TQE 15

Fill tank with same liquid phantom used in waveguide calibration system

Position reference antenna beneath tank with air gap as specified. Connect reference antenna to output of coupler

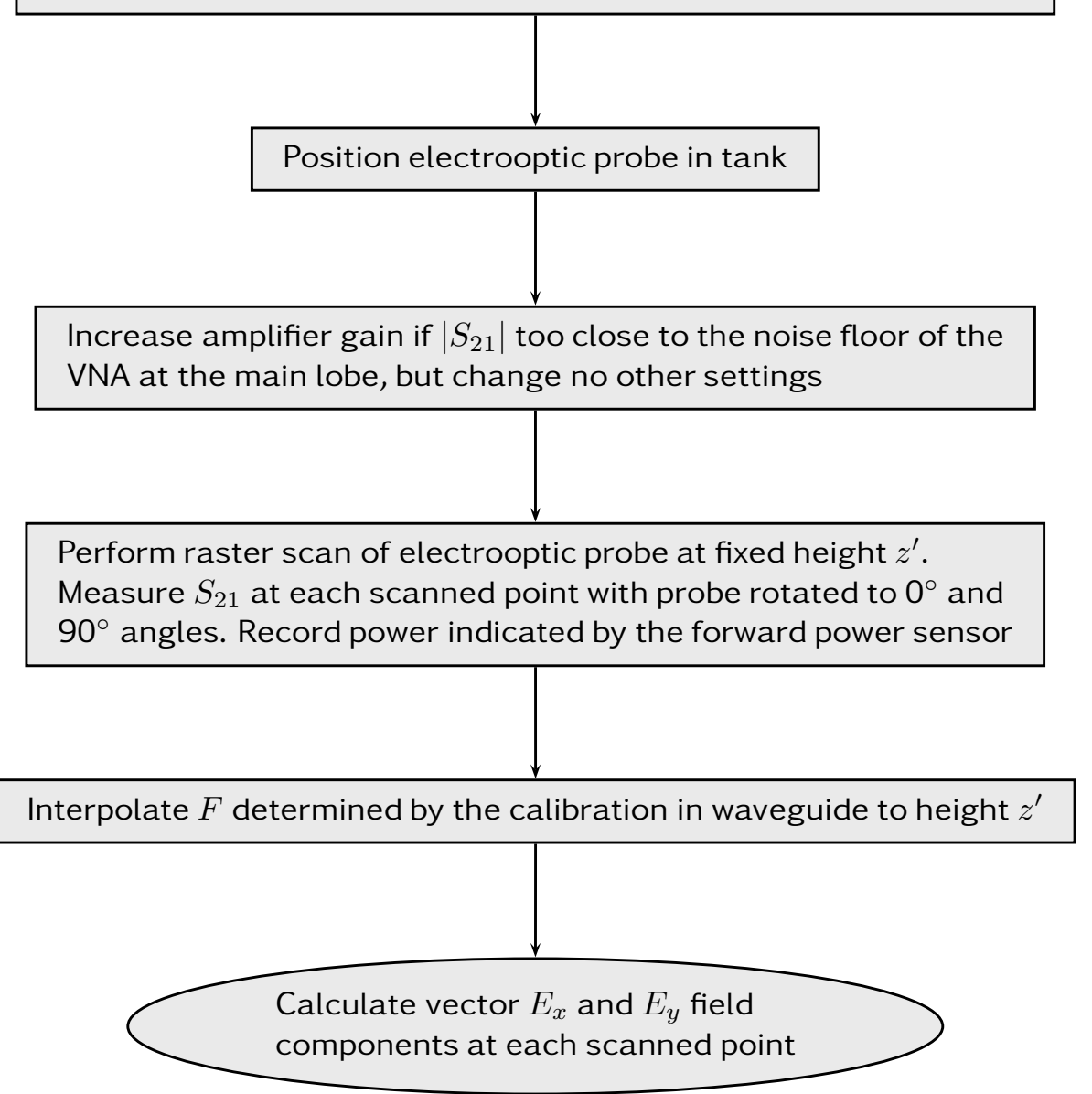

Figure 9: The steps required to obtain a map of vector E-fields in the reference phantom illuminated from beneath by a reference antenna 
NPL Report TQE 15

\subsection{Measurement of the dielectric permittivity and con- ductivity of the liquid phantom}

In the work described, the dielectric permittivity $\epsilon^{\prime}$ and conductivity $\sigma$ of the liquid were obtained from measurements that were made with a coaxial sensor [7] (often referred to as a coaxial probe, or an open-ended coaxial-line probe). It may be noted that it also possible for conductivity to be obtained from measurements of $\left|S_{21}\right|$ as a function of $z$ in the waveguide cell. Measurement of E-fields with miniature probes requires that high power levels are used to ensure that they can be resolved against the background of the noise floor. As a consequence, the liquid phantom can be subject to significant, non-uniform, heating. Evaluation of the uncertainty associated with conductivity requires measurement of temperature variations in the phantom liquid, and dielectricsensor measurements of the temperature coefficients of its permittivity and conductivity.

\subsection{Measurement of calibration factor $F$ by using a waveg- uide cell}

The calibration factor $F(z)(\mathrm{V} / \mathrm{m}$ per S-parameter unit) is obtained from the waveguide measurements from the equation

$$
F(z)=\frac{E(z)}{T(z)}
$$

where $T(z)$ is the scalar transmission coefficient [i.e. $\left.\left|S_{21}\right|\right)$ measured by the VNA and $E(z)$ calculated by using equation (1)]. The sensing axis of the electrooptic probe is aligned with the E-field in the waveguide prior to the measurements. The power at the coupler output at which $F$ is determined is recorded. It is sampled by means of a coupler and side arm power meter (Figure 1). $P_{\mathrm{CO}}$ in equation (5) is related to the side arm power meter reading by

$$
P_{\mathrm{CO}}=P_{\text {side_arm }} \times C .
$$

Measurements of $F$ for a range of $z$ (on which it is observed to depend - see Figures 4 and 5) are taken. These are required in the uncertainty evaluation. Traceable measurements of the following quantities are needed:

$z_{m} \quad$ The separation $(\mathrm{m})$ between the tip of the probe handle and the window in the waveguide cell. 
$z_{0} \quad$ The offset $(\mathrm{m})$ between the dipole element and the tip of the probe handle (see Figure 2).

C The calibration constant of the coupler/side-arm power meters (see Section 4.1).

$W_{\mathrm{T}} \quad$ The transmission coefficient of the connecting cable and the waveguide cell combined (see equation (5)). It is measured from the cable connection at the coaxial output of the coupler, and the interface between the liquid-filled section and the waveguide matching window (see Section 4.2).

$P_{\text {side_arm }} \quad$ The reading of the forward power meter $(\mathrm{W})$. This does not vary significantly with $z$ and is taken to be a constant for each calibration in the waveguide cell.

$a$ and $b \quad$ Waveguide dimensions $(\mathrm{m})$.

f $\quad$ Frequency $(\mathrm{Hz})$.

$\epsilon^{\prime}$ and $\sigma$ The relative permittivity and conductivity $(\mathrm{S} / \mathrm{m})$ of the liquid at the measured frequency. These are dependent on temperature (which must also, therefore, be measured).

$\delta \quad$ The penetration depth (m) calculated from $f, \epsilon^{\prime}$ and $\sigma$ (see equation $(2))$.

\subsection{Measurement of vector E-fields in the reference phan- tom}

The phantom is illuminated by the reference antenna which is placed at a specified distance beneath the phantom. Equations (8) and (9) enable traceable measurements of $E_{x}$ and $E_{y}$ to be obtained over a scanned area. These measurements require the sensing axis of the electrooptic probe to be rotated to align with the $x$ and $y$ axes. As $F$ is a scalar quantity, the measured phase for a vector probe is uncalibrated; nevertheless changes in the phases of measured E-field components fields can be measured. The data required is as follows:

$z_{m}^{*} \quad$ The separation (m) between the tip of the probe handle and the bottom of the reference phantom tank. An asterisk is added to distinguish it from $z_{m}$ measured in the waveguide cell. 
NPL Report TQE 15

$z_{0} \quad$ The offset $(\mathrm{m})$ between the dipole element and the tip of the probe handle (see Figure 2).

$P_{\mathrm{CO}} / P_{\mathrm{ant}} \quad$ The ratio of the power flow to the waveguide cell (for determination of $F(z)$ by calibration) and the reference antenna.

$S_{21} \quad$ The measured vector transmission coefficient.

$F \quad$ The calibration factor, determined in liquid phantom in the waveguide cell $(\mathrm{V} / \mathrm{m}$ per S-parameter unit).

\section{Evaluation of the uncertainty associated with measured E-fields in the reference phantom}

The desired outputs from this work are maps of the $E_{x}$ and $E_{y}$ vector field E-field components inside the reference phantom. The power source is a reference antenna placed a specified distance below the reference phantom. The vector fields measured in the reference phantom have real and imaginary parts $E_{x}=E_{x}^{\prime}+\mathrm{j} E_{x}^{\prime \prime}$ and $E_{y}=E_{y}^{\prime}+\mathrm{j} E_{y}^{\prime \prime}$. These fields are calculated by using equations (8) and (9) for the power level at the coupler output $P_{\mathrm{CO}}$ at which $F$ was determined. It is assumed that reference phantom and waveguide-cell measurements used the same connecting cable.

The uncertainties associated with the E-field components are evaluated from the uncertainty associated with $F$ and the uncertainty associated with $S_{21}$ measured by the robot scan. $S_{21}$ is resolved in both $x$ and $y$ directions, which are here referred to as $\left(S_{21}\right)_{x}=T_{x}^{\prime}+\mathrm{j} T_{x}^{\prime \prime}$ and $\left(S_{21}\right)_{y}=T_{y}^{\prime}+\mathrm{j} T_{y}^{\prime \prime}$. In this report, lowercase $u$ will be used to denote standard uncertainties, i.e. $u(F)$ is the standard uncertainty associated with $F$.

Evaluations of the uncertainty are made from a number of contributions that are identified in this section. Combined uncertainties are obtained in accordance with the law of propagation of uncertainty in the GUM [10, expressions (10) and (13)]. The former (simpler) expression can be used when the input quantities can reasonably be assumed to be independent. 
Noting that $F$ is a scalar quantity, the uncertainty associated with $E_{x}^{\prime}$ [equation (8)] can be evaluated from the expression

$$
\begin{aligned}
u(E) & =g\left\{\left[T_{x}^{\prime} \times u(F)\right]^{2}+\left[F \times u\left(T_{x}^{\prime}\right)\right]^{2}\right\}^{1 / 2}, \\
g & =\sqrt{\frac{P_{\mathrm{CO}}}{P_{\mathrm{ant}}}{ }_{\mathrm{Ang}=0^{\circ}}}, \\
E & \equiv E_{x}^{\prime}\left(z^{*}\right), \\
F & \equiv F\left(z^{*}\right), \quad u(F) \equiv u\left(F\left(z^{*}\right)\right) \quad \text { in reference phantom. }
\end{aligned}
$$

The above top two expressions are equivalent to

$$
u^{2}(E) / E^{2}=u^{2}(F) / F^{2}+u^{2}(T) / T^{2}=a\left[T^{2} u^{2}(F)+F^{2} u^{2}(T)\right] .
$$

Expressions for $E_{x}^{\prime \prime}, E_{y}^{\prime}$ and $E_{y}^{\prime \prime}$ are similar to those in equation (13). The power readings are made with highly-linear sensors; therefore the uncertainty associated with measured power ratios is not explicitly accounted for in equation (13) as it is expected to be negligible.

The $u(F)$ contribution arises from the calibration in the waveguide cell and should therefore be considered to be the result of a Type $\mathrm{B}$ evaluation of standard uncertainty [10, clause 4.3]. The $u\left(T_{x}^{\prime}\right)$ term will be assumed to be the result of a Type A evaluation of standard uncertainty [10, clause 4.2 ], derived from noise associated with the measurement. This assumption is valid for a linear VNA system provided that the signal level is high enough to ensure that leakage is negligible. The Type A evaluation can be obtained from evaluations of uncertainty associated with $T$. An alternative strategy is used here: a Type A contribution for the actual E-field measurements is evaluated from repeated scan measurements. This approach has the advantage that other random causes of uncertainty are represented. These causes could, for example, include the effects of temperature variations within the reference phantom. Equation (13) becomes

$$
u(E)=\left\{g^{2}\left[T_{x}^{\prime} \times u(F)\right]^{2}+u_{\mathrm{A}}^{2}(E)\right\}^{1 / 2}
$$

where $u_{\mathrm{A}}(E)$ is the Type A standard uncertainty that is evaluated from observations of E-field.

Figure 10 shows the full process of evaluating the uncertainty. The Type B contribution associated with the determination of $F$ in the waveguide cell is 
NPL Report TQE 15

shown above the dotted line and is described in detail in Section 5.2. An additional uncertainty contribution represents the Type A component is obtained based on the repeatability of E-field measurements made during scans with the robot.

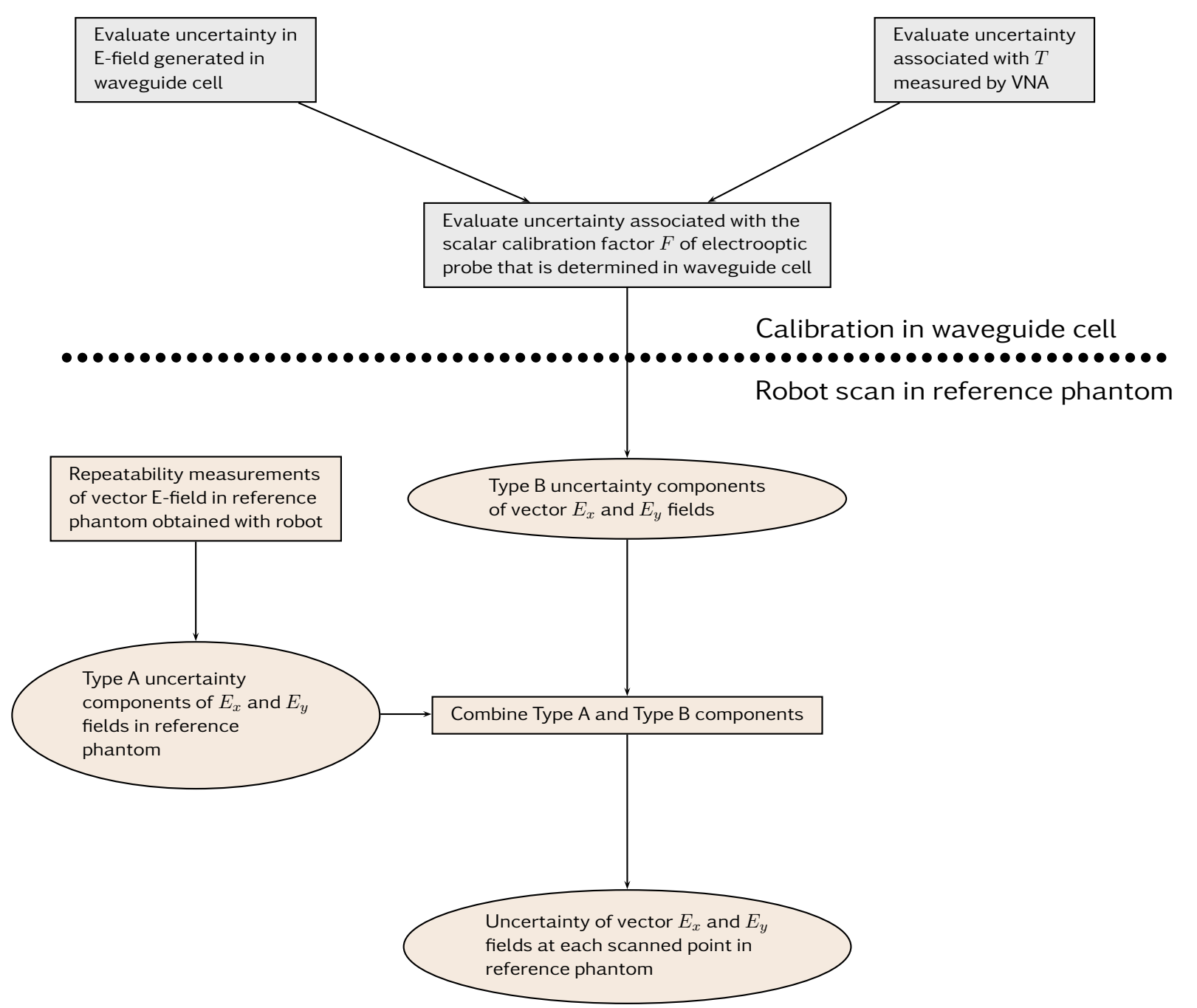

Figure 10: The process used to evaluate uncertainty 


\subsection{Partial derivatives required for calculating uncer- tainty associated with $F$ measured in the waveguide cell}

Using equation (4), the partial derivatives of the E-field magnitude $E \equiv E(z)$ in equation (1) with respect to $a, b, \sigma P_{\mathrm{WG}}, z$ and $\epsilon^{\prime}$ can be expressed as

$$
\begin{aligned}
& \frac{\partial E}{\partial a}=-\frac{E}{2 a}, \quad \frac{\partial E}{\partial b}=-\frac{E}{2 b}, \quad \frac{\partial E}{\partial \sigma}=-\frac{E z}{2} \sqrt{\frac{\mu_{o}}{\epsilon_{o} \epsilon^{\prime}}}, \\
& \frac{\partial E}{\partial P_{\mathrm{WG}}}=\frac{E}{2 P_{\mathrm{WG}}}, \quad \frac{\partial E}{\partial z}=-\frac{E \sigma}{2} \sqrt{\frac{\mu_{0}}{\epsilon_{o} \epsilon^{\prime}}}, \\
& \frac{\partial E}{\partial \epsilon^{\prime}}=\frac{E}{4 \epsilon^{\prime}}\left(z \sigma \sqrt{\frac{\mu_{0}}{\epsilon_{o} \epsilon^{\prime}}}-1\right) .
\end{aligned}
$$

These derivatives evaluated at the estimates of the input quantities will be used as sensitivity coefficients for a calculation of the standard uncertainty $u(E)$ of the magnitude of the E-field in the waveguide by using the law of propagation of uncertainty [10]. The standard uncertainty associated with $F$ is given by

$$
u(F)=\sqrt{[u(E) / T]^{2}+\left[E u(T) / T^{2}\right]^{2}},
$$

where $u(T)$ is the uncertainty associated with the measured $T$. 
NPL Report TQE 15

\subsection{Identification of uncertainty contributions associ- ated with measurement of $F(z)$ with the waveguide system}

The law of propagation of uncertainty for uncorrelated quantities [10, clause 5.1] can be used to evaluate $u(F)$ [see equation (13)] from the partial derivatives in Section 5.1 and the uncertainties associated with the quantities on which it depends on the assumption that these contributions are independent. Uncertainties associated with the measurands from which $F$ is calculated (see Figure 8) must first be identified and then evaluated.

Tables 2, 3, 4 and 5 show the contributions associated with the scalar calibration factor $F$. These are based on an NPL procedure.

Table 2: Components of the standard uncertainty $u_{P}$ of power input $P_{\mathrm{CO}}$ to the waveguide measured at the coaxial port

\begin{tabular}{|l|c|c|c|}
\hline Description & Type & $\begin{array}{l}\text { Probability } \\
\text { distribution }\end{array}$ & $\begin{array}{c}\text { Symbol for } \\
\text { standard } \\
\text { uncertainty }\end{array}$ \\
\hline \hline $\begin{array}{l}\text { Reference sensor } \\
\text { calibration accuracy }\end{array}$ & Type B & Normal & $u_{\text {RCAL }}$ \\
\hline $\begin{array}{l}\text { Reference sensor } \\
\text { drift }\end{array}$ & Type B & Rectangular & $u_{\text {RDRIFT }}$ \\
\hline $\begin{array}{l}\text { Reference sensor } \\
\text { linearity }\end{array}$ & Type B & Rectangular & $u_{\text {RLIN }}$ \\
\hline $\begin{array}{l}\text { Reference power meter } \\
\text { resolution }\end{array}$ & Type B & Rectangular & $u_{\text {RRES }}$ \\
\hline $\begin{array}{l}\text { Zero error of } \\
\text { reference power meter }\end{array}$ & Type B & Rectangular & $u_{\text {RZE }}$ \\
\hline $\begin{array}{l}\text { Zero error of } \\
\text { side arm power meter }\end{array}$ & Type B & Rectangular & $u_{\text {SRES }}$ \\
\hline $\begin{array}{l}\text { Resolution of } \\
\text { side arm power meter }\end{array}$ & Type B & Normal & $u_{\mathrm{vHar}}$ \\
\hline $\begin{array}{l}\text { Signal harmonics } \\
\text { and noise }\end{array}$ & Type B & Rectangular & $u_{\text {Con }}$ \\
\hline $\begin{array}{l}\text { Connector } \\
\text { repeatability }\end{array}$ & & $u_{\text {SZE }}$ \\
\hline
\end{tabular}


Table 3: Components of the standard uncertainty $u_{\mathrm{W}}$ of the waveguide powertransmission $W_{\mathrm{T}}$

\begin{tabular}{|l|c|c|c|}
\hline Description & Type & $\begin{array}{l}\text { Probability } \\
\text { distribution }\end{array}$ & $\begin{array}{l}\text { Symbol for } \\
\text { standard } \\
\text { uncertainty }\end{array}$ \\
\hline \hline $\begin{array}{l}\text { f Power reflected back } \\
\text { from the waveguide system } \\
\text { with liquid in situ. }\end{array}$ & Type B & U-shaped & $u_{\mathrm{M}}$ \\
Hamada \& Watanabe [3, equation (8)] & Type B & Normal & $u_{\ell}$ \\
\hline $\begin{array}{l}* \text { Power loss in } \\
\text { coaxial transformer }\end{array}$ & & & \\
\hline $\begin{array}{l}\text { Power loss in dielectric } \\
\text { window }\end{array}$ & Type B & Normal & $u_{\mathrm{w}}$ \\
\hline
\end{tabular}

$\ddagger$ Accounts for a combination of the mismatches of the waveguide/coaxial transformer and the dielectric window/liquid. This is referred to as $M_{\text {COUPLER }}$ in the NPL procedure.

* NPL procedure refers to this as PTF.

Table 4: Components of the standard uncertainty of transmission coefficients $S_{21}$ that are measured by using the VNA. These are contributions to the uncertainty in the calibration factor $F$ that is determined from the measurements in the waveguide cell

\begin{tabular}{|c|c|c|c|}
\hline Description & Type & $\begin{array}{l}\text { Probability } \\
\text { distribution }\end{array}$ & $\begin{array}{l}\text { Symbol for } \\
\text { standard } \\
\text { uncertainty }\end{array}$ \\
\hline \hline $\begin{array}{l}\text { Independent noise on each } \\
\text { component (real and imag.) } \\
\text { measured with the VNA }\end{array}$ & Type A & Normal & $u_{\mathrm{TA}}$ \\
\hline $\begin{array}{l}\text { Noise on } T=\left|S_{2,1}\right| \\
\text { measured with the VNA }\end{array}$ & Type A & Normal & $u_{\mathrm{TA}}$ \\
\hline $\begin{array}{l}\text { Drift of measurements } \\
\text { with the VNA }\end{array}$ & Type A & Normal & $u_{\mathrm{TD}}$ \\
\hline $\begin{array}{l}\text { Effect on } T \text { of } \\
\text { non-repeatability of } \\
\text { fibreoptic connections }\end{array}$ & Type A & Normal & $u_{\mathrm{TF}}$ \\
\hline
\end{tabular}


NPL Report TQE 15

Table 5: Measurands and associated uncertainty contributions that determine the Efield set up in the waveguide cell at the locality of the electrooptic probe

\begin{tabular}{|c|c|c|c|c|}
\hline Measurand & Description & Type & $\begin{array}{l}\text { Probability } \\
\text { distribution }\end{array}$ & $\begin{array}{l}\text { Symbol for } \\
\text { standard } \\
\text { uncertainty }\end{array}$ \\
\hline$P_{\mathrm{CO}}$ & $\begin{array}{l}\text { Input power (at coupler } \\
\text { output). } \\
\text { See Table } 2\end{array}$ & See Table 2 & See Table 2 & $u_{P}$ \\
\hline$W_{\mathrm{T}}$ & $\begin{array}{l}\text { Power transmission } \\
\text { fraction for WG } \\
\text { See Table } 3\end{array}$ & See Table 3 & See Table 3 & $u_{W}$ \\
\hline- & $\begin{array}{l}\$ \text { Non-uniformity of power } \\
\text { in locality of probe }\end{array}$ & Type B & Rectangular & $u_{\mathrm{nu}}$ \\
\hline- & $\begin{array}{l}\text { Accuracy of setting } \\
\text { probe at centre of waveguide }\end{array}$ & Type A & Normal & $u_{Y}$ \\
\hline$t$ & $\begin{array}{l}\text { The temperature of the } \\
\text { phantom liquid }\end{array}$ & $\begin{array}{l}\text { Type B } \\
\text { (largely) }\end{array}$ & Normal & $u_{t}$ \\
\hline$\sigma$ & $\begin{array}{l}\text { Conductivity of the } \\
\text { phantom liquid }\end{array}$ & Type B & Normal & $u_{\sigma}$ \\
\hline$\epsilon$ & $\begin{array}{l}\text { Real part of the relative } \\
\text { permittivity of the liquid }\end{array}$ & Type B & Normal & $u_{\epsilon}$ \\
\hline $\mathrm{tc}_{\epsilon}$ & $\begin{array}{l}\text { Temperature coefficient } \\
\text { of } \epsilon\end{array}$ & Type B & Normal & $u_{\mathrm{tc} \epsilon}$ \\
\hline $\mathrm{tc}_{\sigma}$ & $\begin{array}{l}\text { Temperature coefficient } \\
\text { of } \sigma\end{array}$ & Type B & Normal & $u_{\mathrm{tc} \sigma}$ \\
\hline$a$ & Waveguide width & Type B & Normal & $u_{a}$ \\
\hline$b$ & Waveguide height & Type B & Normal & $u_{b}$ \\
\hline$z_{m}$ & $\begin{array}{l}\text { Probe positioning } \\
\text { (distance between probe } \\
\text { and dielectric window) }\end{array}$ & Type A & Normal & $u_{z m}$ \\
\hline$z_{\mathrm{O}}$ & $\begin{array}{l}\text { Sensor offset } \\
\text { (distance between sensor } \\
\text { and end of probe) }\end{array}$ & Type A & Normal & $u_{z o}$ \\
\hline
\end{tabular}

$\$$ This item refers to the fact that fields in the region of the probe are subject to gradients (they are at maximum on axis) [3]. Referred to by $\Delta E_{01}$ in NPL procedure. 
Table 6: $F(z)$ and the associated standard uncertainty, $u(F)$

\begin{tabular}{c|c|c|c} 
Frequency $(\mathrm{MHz})$ & $z(\mathrm{~mm})$ & $F \mathrm{~V} / \mathrm{m}$ & $u(F) \mathrm{V} / \mathrm{m}$ \\
\hline 900 & 15.25 & 35500 & 2500 \\
2450 & 15.25 & 62900 & 1800 \\
\hline
\end{tabular}

Table 7: Measurands and their estimates and associated standard uncertainties that are used to determine $F(z)$ in the waveguide cell for the $900 \mathrm{MHz}$ system

\begin{tabular}{|c|c|c|c|c|c|}
\hline Measurand & value & \multicolumn{3}{|c|}{ Standard uncertainty } & Note \\
\hline$P_{\text {in }}$ & $1.65 \mathrm{~W}$ & $u_{\text {Pin }}$ & & $1.32 \%$ & $\begin{array}{l}\ddagger P_{\mathrm{WG}} \\
\text { NPL Proc. Table } 3\end{array}$ \\
\hline \multirow{3}{*}{$W_{\mathrm{T}}$} & \multirow{3}{*}{$\diamond 0.9954$} & ${ }^{*} u_{\mathrm{M}}$ & & $0.84 \%$ & $\ddagger M_{\text {COUPLER }}$ \\
\hline & & $u_{\ell}$ & & $0.46 \%$ & $\ddagger \mathrm{PTF}$ \\
\hline & & $u_{w}$ & & $0.1 \%$ & $\ddagger L_{\text {WINDOW }}$ \\
\hline$\epsilon$ & 42.4 & $u_{\epsilon}$ & 0.3 & $0.7 \%$ & at $21^{\circ} \mathrm{C}$ \\
\hline$t c_{\epsilon}$ & -0.04 per ${ }^{\circ} \mathrm{C}$ & $\dagger$ & & & \\
\hline$\sigma$ & $0.93 \mathrm{~S} \mathrm{~m}^{-1}$ & $u_{\sigma}$ & $0.007 \mathrm{~S} / \mathrm{m}$ & $0.7 \%$ & at $21^{\circ} \mathrm{C}$ \\
\hline$t c_{\sigma}$ & $0.12 \mathrm{~S} \mathrm{~m}^{-1}$ per ${ }^{\circ} \mathrm{C}$ & $\dagger$ & & & \\
\hline$t$ & $21^{\circ} \mathrm{C}$ & $u_{t}$ & 1 & $1.3 \%$ & \\
\hline$a$ & $247.65 \mathrm{~mm}$ & $u_{a}$ & $0.75 \mathrm{~mm}$ & $0.3 \%$ & \\
\hline$b$ & $123.83 \mathrm{~mm}$ & $u_{b}$ & $0.25 \mathrm{~mm}$ & $0.3 \%$ & \\
\hline$z$ & $15.25 \mathrm{~mm}$ & $u_{z}$ & $0.2 \mathrm{~mm}$ & $1.3 \%$ & $z=z_{m}+z_{o}$ \\
\hline$T$ & Depends on $z$ & $u_{\mathrm{T}}$ & 0.0001 Units & Varies & \\
\hline
\end{tabular}

$\ddagger$ Nomenclature from NPL procedure

* Reflected power $22.24 \mathrm{~dB}$ down with liquid in situ.

$\diamond$ Power transmission coefficient of waveguide cell and connecting cable from coaxial output of coupler up to dielectric window [see equation (5)].

$\dagger$ Temperature deviations from $21^{\circ} \mathrm{C}$ and non-uniformity are treated as uncertainties rather than correctable errors, so uncertainties associated with temperature coefficients, $u_{\mathrm{tc} \epsilon}$ and $u_{\mathrm{tc} \sigma}$, are not required. 
NPL Report TQE 15

Table 8: Measurands and their estimates and associated standard uncertainties that are used to determine $F(z)$ in the waveguide cell for the $2450 \mathrm{MHz}$ system

\begin{tabular}{|c|c|c|c|c|c|}
\hline Measurand & value & \multicolumn{3}{|c|}{ Standard uncertainty } & Note \\
\hline \hline$P_{\text {in }}$ & $1.71 \mathrm{~W}$ & $u_{\text {Pin }}$ & & $1.32 \%$ & $\begin{array}{l}\ddagger P_{\text {WG }} \\
\text { NPL Proc. Table 3 }\end{array}$ \\
\cline { 3 - 6 } & & & & $0.84 \%$ & $\ddagger M_{\text {COUPLER }}$ \\
\hline \multirow{2}{*}{$W_{\mathrm{T}}$} & \multirow{2}{*}{0.9941} & $u_{\mathrm{M}}$ & & $0.46 \%$ & $\ddagger$ PTF \\
\cline { 3 - 6 } & & $u_{w}$ & & $0.1 \%$ & $\ddagger L_{\text {WINDOW }}$ \\
\hline$\epsilon$ & 38.7 & $u_{\epsilon}$ & 0.3 & $0.8 \%$ & at $21^{\circ} \mathrm{C}$ \\
\hline$t c_{\epsilon}$ & $-0.2 \mathrm{per}^{\circ} \mathrm{C}$ & $\dagger$ & & & at $21^{\circ} \mathrm{C}$ \\
\hline$\sigma$ & $1.873 \mathrm{~S} \mathrm{~m}^{-1}$ & $u_{\sigma}$ & $0.02 \mathrm{~S} / \mathrm{m}$ & $1.0 \%$ & \\
\hline$t c_{\sigma}$ & $0.13 \mathrm{~S} \mathrm{~m}^{-1} \mathrm{per}^{\circ} \mathrm{C}$ & $\dagger$ & & & \\
\hline$t$ & $21^{\circ} \mathrm{C}$ & $u_{t}$ & 1 & $1.3 \%$ & \\
\hline$a$ & $109.2 \mathrm{~mm}$ & $u_{a}$ & $0.2 \mathrm{~mm}$ & $0.2 \%$ & \\
\hline$b$ & $55.6 \mathrm{~mm}$ & $u_{b}$ & $0.1 \mathrm{~mm}$ & $0.2 \%$ & \\
\hline$z$ & $15.25 \mathrm{~mm}$ & $u_{z}$ & $0.2 \mathrm{~mm}$ & $1.3 \%$ & $z=z_{m}+z_{o}$ \\
\hline$T$ & Depends on $z$ & $u_{\mathrm{T}}$ & $0.00003 \mathrm{Units}$ & Varies & \\
\hline
\end{tabular}

$\ddagger$ Nomenclature from NPL procedure

* Reflected power $22.24 \mathrm{~dB}$ down with liquid in situ.

$\diamond$ Power transmission coefficient of waveguide cell and connecting cable from coaxial output of coupler up to dielectric window [see equation (5)].

$\dagger$ Temperature deviations from $21^{\circ} \mathrm{C}$ and non-uniformity are treated as uncertainties rather than correctable errors, so uncertainties associated with temperature coefficients, $u_{\mathrm{tc} \epsilon}$ and $u_{\mathrm{tc} \sigma}$, are not required.

\section{Results}

Table 6 shows $F$ and $u(F)$ determined by using waveguide cells at $900 \mathrm{MHz}$ and $2450 \mathrm{MHz}$. Equation (5.1) was used to evaluate $u(F)$. The individual uncertainty components are shown in Tables 7 and 8 . The calibrated electrooptic probe was then used to scan the E-field in reference phantoms illuminated by three antennas (Table 9). The liquid phantoms [9] used for the calibrations in waveguide were used again for these measurements. Figures 4 and 5 show that there is a slight dependence of $F$ on $z$. This may be due to factors such as the construction of the probe handle (which includes layers of air and polymer that surround the electrooptic sensor). The variation of $F$ with $z$ measured in the waveguide is fitted by a polynomial, from which $F\left(z^{*}\right)$ (where $z^{*}$ is the height of the electrooptic sensor in the reference phantom) is calculated. Figures 4 and 5 show that $u(F)$ does not show a significant systematic trend for the gap 
used, $z=z^{*}=15.25 \mathrm{~mm}$ (the observed variations are predominantly noise associated with $T$ ). It must be assumed that $F$ is not changed when the probe is re-located from the waveguide cell to the reference phantom. Marginal effects on $F$ may occur because the sensitivity of the electrooptic probe depends on $\epsilon$ and $\sigma$ of the surrounding medium (the liquid phantom), which are temperature dependent and therefore subject to induced heating as well as changes in the room temperature. It was not possible to study this aspect during the work described in this report.

Each antenna is designed to operate at one frequency in proximity to a reference phantom at a gap that is specified by the manufacturer. E-field maps are shown in Figure 11 for the ART-250 antenna at $900 \mathrm{MHz}$, and in Figure 12 for the ART-219 antenna at $2450 \mathrm{MHz}$.

Table 9: Specifications for antennas and reference phantoms

\begin{tabular}{l|c|c|c|c}
\hline $\begin{array}{l}\text { Antenna } \\
\text { Model }\end{array}$ & $\begin{array}{c}\text { Frequency } \\
(\mathrm{MHz})\end{array}$ & $\begin{array}{l}\text { Specified gap } \\
\text { between antenna } \\
\text { and phantom }(\mathrm{mm})\end{array}$ & Target $\epsilon^{\prime}$ & Target $\sigma(\mathrm{S} / \mathrm{m})$ \\
\hline ART-250 & 900 & 11 & 41.5 & 0.97 \\
ART-219 & 2450 & 6 & 39.2 & 1.80 \\
ART-220 & 5200 & 11 & 36.0 & 4.66 \\
\hline
\end{tabular}

Since the signal to noise ratio at $5200 \mathrm{MHz}$ was very poor, satisfactory measurements of the E-field in the reference phantom were not obtainable. This deficiency is a consequence of the short penetration depth $(7 \mathrm{~mm})$. The height of the waveguide used at this frequency (WG12) is only a few times greater than the diameter of the probe which will increase the perturbing effect of the probe (Figure 2) on the E-field, which in turn will cause an error in the value of $F$. It was not possible to quantify this error with the available resources. For these reasons, measurements made with the ART-220 antenna $(5200 \mathrm{MHz})$ are not presented.

Scanned measurements on the reference phantom illuminated by each antenna were performed three times to allow the Type A uncertainty evaluation. Tables 10 and 11 show subsets of the data at $900 \mathrm{MHz}$ in locations close to the maximum and minimum of $\left|E_{x}\right|$. At each $(X, Y)$ location, the variance of the measurements was determined. The standard uncertainty associated with the Type A evaluation was taken as the square root of the average variance. Some points around the periphery of the scan were excluded as there were some incorrect readings which are associated with the instrumentation (these can 
NPL Report TQE 15

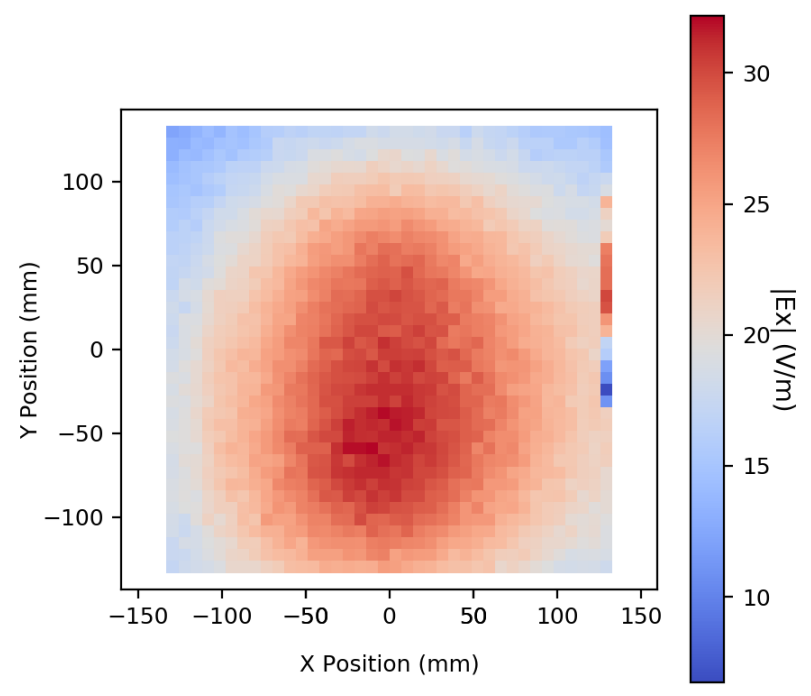

(a) $\left|E_{x}\right|$

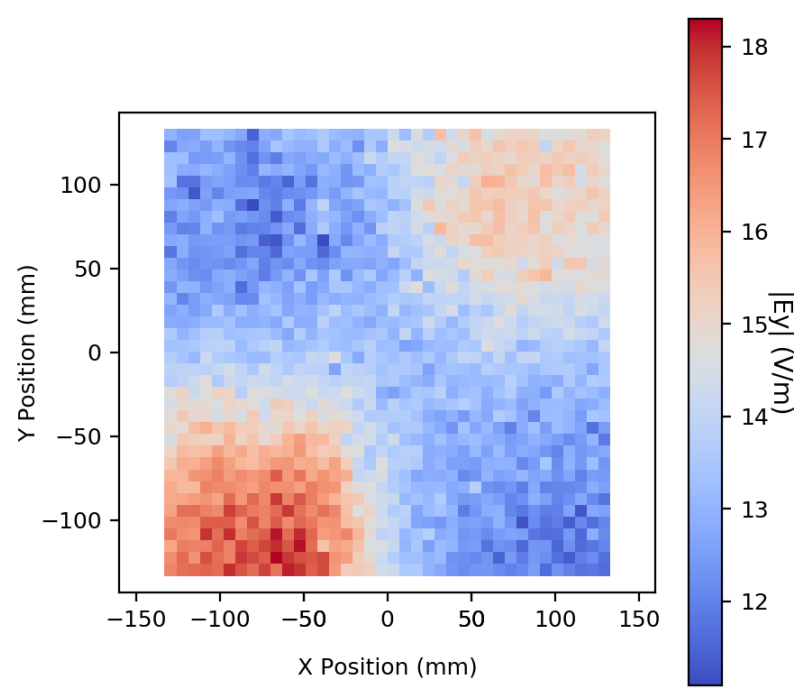

(b) $\left|E_{y}\right|$

Figure 11: Colour maps of the magnitude of the E-field components in the reference phantom. This data was obtained for reference antenna model ART-250 at $900 \mathrm{MHz}$. The tip of the antenna was $10 \mathrm{~mm}$ beneath the phantom. The maps are determined for an input power of $1.66 \mathrm{~W}$. The height of the sensing element, defined by Figure 2, was $z^{*}=15.25 \mathrm{~mm}$

Page 28 of 33 
NPL Report TQE 15

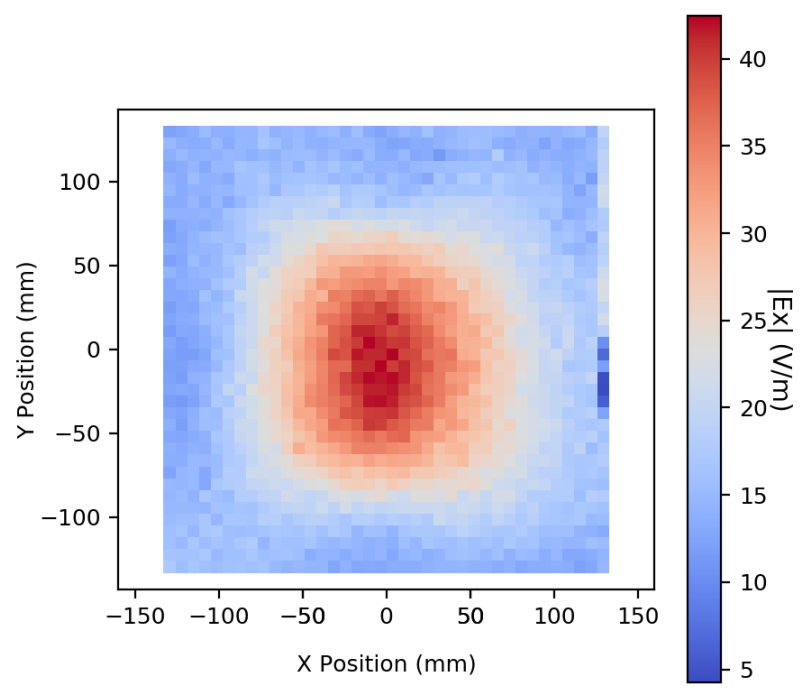

(a) $\left|E_{x}\right|$

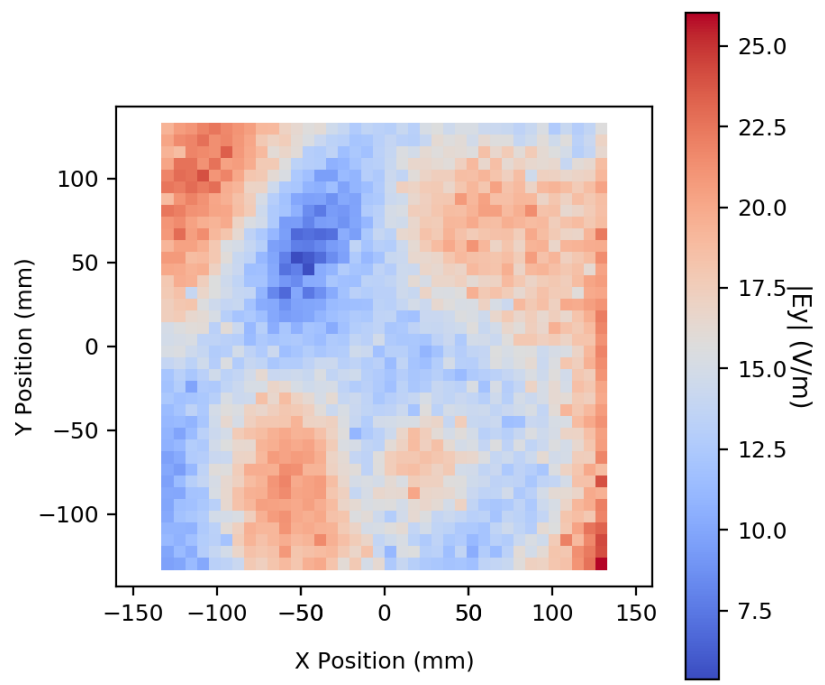

(b) $\left|E_{y}\right|$

Figure 12: Colour maps of the magnitude of the E-field components in the reference phantom. This data was obtained for reference antenna model ART-219 at $2450 \mathrm{MHz}$. The tip of the antenna was $6 \mathrm{~mm}$ beneath the phantom. The maps are determined for an input power of $1.71 \mathrm{~W}$. The height of the sensing element, defined by Figure 2, was $z^{*}=15.25 \mathrm{~mm}$

Page 29 of 33 
be seen in Figure 11). The Type A standard uncertainty contributions were evaluated as $1.5 \mathrm{~V} / \mathrm{m}$ and $5.1 \mathrm{~V} / \mathrm{m}$ at $900 \mathrm{MHz}$ and $2450 \mathrm{MHz}$ respectively.

Table 10: Three sets of measurements of $E_{x}$ in the reference phantom at $900 \mathrm{MHz}$ (selected high-value points). Set 3 is shown in Figure 11

\begin{tabular}{|c|c||c|c||c|c||c|c|}
\cline { 2 - 8 } \multicolumn{1}{l||}{} & \multicolumn{5}{c|}{ E-field $(\mathrm{V} / \mathrm{m})$} \\
\hline \multicolumn{2}{|c||}{ Position $(\mathrm{mm})$} & \multicolumn{2}{c|}{ Set 1 } & \multicolumn{2}{c|}{ Set 2 } & \multicolumn{2}{c|}{ Set 3 } \\
\hline $\mathrm{X}$ & $\mathrm{Y}$ & $E_{x}^{\prime}$ & $E_{x}^{\prime \prime}$ & $E_{x}^{\prime}$ & $E_{x}^{\prime \prime}$ & $E_{x}^{\prime}$ & $E_{x}^{\prime \prime}$ \\
\hline 0 & -42 & -10.40 & 26.32 & -10.94 & 28.35 & -10.42 & 29.34 \\
-7 & -42 & -9.76 & 26.70 & -9.68 & 28.16 & -10.38 & 29.58 \\
0 & -49 & -9.86 & 26.64 & -10.17 & 28.42 & -9.60 & 29.92 \\
-14 & -56 & -9.84 & 26.85 & -9.02 & 28.61 & -8.95 & 30.63 \\
\hline
\end{tabular}

Table 11: Three sets of measurements of $E_{x}$ in the reference phantom at $900 \mathrm{MHz}$ (selected low-value points). Set 3 is shown in Figure 11

\begin{tabular}{|c|c|c|c||c|c||c|c|}
\cline { 3 - 8 } \multicolumn{1}{c||}{} & \multicolumn{5}{c|}{ E-field $(\mathrm{V} / \mathrm{m})$} \\
\hline \multicolumn{2}{|c||}{ Position $(\mathrm{mm})$} & \multicolumn{2}{|c|}{ Set 1 } & \multicolumn{2}{|c|}{ Set 2 } & \multicolumn{2}{c|}{ Set 3 } \\
\hline $\mathrm{X}$ & $\mathrm{Y}$ & $E_{x}^{\prime}$ & $E_{x}^{\prime \prime}$ & $E_{x}^{\prime}$ & $E_{x}^{\prime \prime}$ & $E_{x}^{\prime}$ & $E_{x}^{\prime \prime}$ \\
\hline-105 & 119 & -2.10 & 11.06 & -0.46 & 13.36 & -0.40 & 14.58 \\
-112 & 119 & -0.94 & 11.23 & -1.26 & 12.53 & -0.02 & 13.91 \\
-119 & 119 & -1.78 & 10.87 & -0.89 & 13.29 & -0.09 & 14.13 \\
-112 & 112 & -2.06 & 11.22 & -0.78 & 13.93 & -0.21 & 15.16 \\
\hline
\end{tabular}

Following the scheme advocated in Figure 10, the uncertainty can be calculated as follows: The calibration factor at $900 \mathrm{MHz}$ is $F=35500 \mathrm{~V} / \mathrm{m}$ per S-parameter unit. The standard uncertainty associated with $F$ is evaluated as $2500 \mathrm{~V} / \mathrm{m}$ per S-parameter unit (see Table 6). In the high E-field region $(30 \mathrm{~V} / \mathrm{m})$ of Figure 11 so, using equation $(7), g \times T=30 / 35500=0.0008$. By using equation (14) the uncertainty in $E_{x}$ is calculated as

$$
u\left(\left|E_{x}\right|\right)=\sqrt{(1.5 \mathrm{~V} / \mathrm{m})^{2}+(2500 \mathrm{~V} / \mathrm{m} \times 0.0008)^{2}}=2.5 \mathrm{~V} / \mathrm{m} .
$$

The expanded measurement uncertainty associated with $\left|E_{x}\right|$ is approximately $15 \%$ at coverage factor $k=2$. The Type A contribution associated with the scanned measurements is larger than the Type B contribution associated with the calibration in the waveguide cell. This is partly because the E-fields in the reference phantom were weaker than those in the waveguide cell, so $S_{21}$ was closer to the noise floor. 
Similar calculations can be made at $2450 \mathrm{MHz}$ by using the data in Table 6 and the value of $F$ determined in the WG8-size waveguide cell. In the high Efield region $(40 \mathrm{~V} / \mathrm{m})$ of Figure $12 E=40 \mathrm{~V} / \mathrm{m}$ so $g \times T=40 / 62900=0.0006$. The standard uncertainty in $E_{x}$ is

$$
u\left(\left|E_{x}\right|\right)=\sqrt{(5.1 \mathrm{~V} / \mathrm{m})^{2}+(1800 \mathrm{~V} / \mathrm{m} \times 0.0006)^{2}}=5.2 \mathrm{~V} / \mathrm{m} .
$$

The expanded measurement uncertainty associated with $\left|E_{x}\right|$ is approximately $25 \%$ at coverage factor $k=2$.

An assessment of relative phase uncertainty was also made on the basis of measurements in high E-field locations (to ensure that measurements of $T$ significantly exceed the associated random noise). Only relative phase is measured; therefore the requirement is to evaluate the uncertainty caused by phase drift during each scan with the robot, rather than between one scan and another. A point at the same (high E-field) location for the three scans was chosen as a phase reference point. Point-to point phase variations within each set relative to this point were then calculated. The RMS phase drift between three scans was used as the basis of the uncertainty evaluation. It was found that the expanded uncertainty associated with the relative phase at $900 \mathrm{MHz}$ and $2450 \mathrm{MHz}$ were respectively $1.4^{\circ}$ and $4.5^{\circ}$ at coverage factor $k=2$, which are surprisingly small values.

\section{Conclusion}

A fibre-coupled electrooptic probe was built into a leakproof housing to enable measurements of vector E-fields in tissue-equivalent liquid phantoms. The probe contains no metal parts, other than a miniature dipole attached to the sensor (a lithium niobate chip), and therefore causes minimal disturbance to measured fields. E-fields are sensed by optical modulation of laser light at the signal frequency, which is then demodulated by using a high speed photodiode. A Vector Network Analyser is used as the RF source and receiver.

Waveguide cells were used to calibrate the electrooptic probe system, which was then used to characterise reference antennas at $900 \mathrm{MHz}$ and $2450 \mathrm{MHz}$. This entailed positioning the reference antennas beneath liquid phantoms, and then measuring complex $E_{x}$ and $E_{y}$ field components over a plane inside the phantom for a specified power input, $P_{\mathrm{CO}}$. 
NPL Report TQE 15

Each characterised reference antenna can be used to set up known complex E-fields in a 'test' phantom. The field magnitude is proportional to the square root of the input power to the antenna, which must therefore be measured so that an appropriate scaling factor can be applied.

An example application is for calibrating vector-based instruments for SAR measurement, such as the ARTMAN system that is manufactured by the ArtFi company [4]. This uses a rectangular tank which contains an array of antennas that are used for sensing E-fields. The tank is filled by a broadband phantom.

\section{Acknowledgements}

This work was carried out as part of project 16NRM07 (Vector SAR, "SAR measurement using vector probes") which received funding from the EMPIR program co-financed by the Participating States and from the European Union's Horizon 2020 research and innovation programme. The authors thank the Art-Fi company for lending the reference antennas to NPL, and Dan Hart (NPL) for programming the robot.

\section{References}

[1] IEC 62209-3:2019 Measurement procedure for the assessment of specific absorption rate of human exposure to radio frequency fields from handheld and body-mounted wireless communication devices - Part 3: Vector measurement-based systems (frequency range of $600 \mathrm{MHz}$ to $6 \mathrm{GHz}$ ). International Electrotechnical Commission, Geneva. 2019.

[2] Zicheng Liu et al. "Discrepancies of Measured SAR between Traditional and Fast Measuring Systems". In: International Journal of Environmental Research and Public Health 17.2221 (2020). URL: https://doi.org/ 10.3390/ijerph17062111.

[3] Lira Hamada and Soichi Watanabe. "2-7 Calibration of SAR Probe". In: Journal of National Institute of Information and Communications Technology 63.1 (2016). Ed. by Yasushi Matsumoto, pp. 135-150. URL: http : / / www . nict.go.jp/publication/shuppan/kihou-journal / journal-vol63no1.html. 
[4] B. Derat et al. "A novel technology for fast and accurate specific absorption rate measurement". In: 2013 International Workshop on Antenna Technology (iWAT). IEEE, Mar. 2013. DOI: 10.1109/iwat.2013. 6518366.

[5] IEEE 1528-2013 Recommended Practice for Determining the Peak SpatialAverage Specific Absorption Rate (SAR) in the Human Head from Wireless Communications Devices: Measurement Techniques. DOI: 10.1109/ ieeestd.2013.6589093.

[6] IEEE C95.1-2005 Standard for Safety Levels with Respect to Human Exposure to Radio Frequency Electromagnetic Fields, $3 \mathrm{kHz}$ to $300 \mathrm{GHz}$. DOI: $10.1109 /$ ieeestd.2006.99501.

[7] A. P. Gregory and R. N. Clarke. "Dielectric metrology with coaxial sensors". In: Measurement Science and Technology 18.5 (2007), pp. $1372-$ 1386. DOI: $10.1088 / 0957-0233 / 18 / 5 / 026$.

[8] S. Ramo, J.R. Whinnery, and T. Van Duzer. Fields and Waves in Communication Electronics. Handbook of automatic computation and control. J. Wiley, 1965.

[9] B. Loader, A. Gregory, and R. Mouthaan. "Formulation and Properties of Liquid Phantoms, $1 \mathrm{MHz}$ to $10 \mathrm{GHz}$ ". Tech. rep. TQE9. Teddington, UK: National Physical Laboratory, 2018. URL: http://eprintspublications . npl.co.uk/7946/.

[10] BIPM et al. Evaluation of measurement data - Guide to the expression of uncertainty in measurement. Joint Committee for Guides in Metrology, JCGM 100:2008. URL: http: / / www . bipm .org/utils/common/ documents/jcgm/JCGM\%5C_100\%5C_2008\%5C_E.pdf. 